\title{
Coupling of Realistic Rate Estimates with Genomics for Assessing Contaminant Attenuation and Long-Term Plume Containment
}

\author{
Kent S. Sorenson, Jr., \\ North Wind Environmental, Inc. \\ P.O. Box 51174 \\ Idaho Falls, ID 83405
}

\begin{abstract}
Natural attenuation of TCE under aerobic conditions at the INEEL Test Area North site was demonstrated largely on the basis of preferential loss of TCE relative to conservative solutes (PCE and H-3) along groundwater flow paths. First order degradation half-lives were calculated from the rate of preferential TCE loss. We are utilizing the same approach at other DOE sites that have aerobic TCE plumes to determine if aerobic natural attenuation of TCE is rapid enough at these sites to be environmentally significant, i.e. if natural attenuation can reduce concentrations to acceptable levels before groundwater reaches potential receptors. The first step in this process was to identify TCE plumes at DOE sites that have the appropriate site conditions and data needed to perform this analysis. The site conditions include the presence of TCE in groundwater at appreciable concentrations in an aerobic aquifer, a co-mingled contaminant that can be used as a conservative tracer (e.g. PCE, H-3, Tc-99), a flow path that represents at least a decade of travel time, and several monitoring wells located along this flow path. Candidate sites were identified through interviews with knowledgeable individuals in the DOE system and by screening the U.S. Dept. of Energy Groundwater Database using the keywords ?TCE? and ?groundwater?. The initial screening yielded 25 plumes for consideration. These sites had anywhere from one to 37 individual plumes containing TCE. Of the 25 sites, 13 sites were further evaluated because they met the screening criteria or were promising. After contacting DOE personnel from the respective sites, they were divided into three groups: 1) sites that meet all the project criteria, 2) sites that could potentially be used for the project, and 3) DOE sites that did not meet the criteria. The five sites with plumes that met the criteria were: Brookhaven National Laboratory, Lawrence Livermore National Laboratory, Paducah Gaseous Diffusion Plant, Rocky Flats Environmental Technology Site, and the Savannah River Site. Detailed characterization data from the promising plumes is being entered into our database as it is received. The next step is to calculate natural attenuation half-life values for all of these plumes. We will next identify the plumes in which natural attenuation via aerobic degradation of TCE is fast enough that it may be relevant as a component of a remedy. We will then select at least one of these sites and either modify an existing groundwater transport model or, if necessary, create a new model, for this plume. This model will initially include first order decay of TCE, and degradation will be parameterized using the half-live values determined from the field data. The models will be used to simulate the evolution of the TCE plume and to predict concentrations as a function of time at property lines or other artificial boundaries, and where potential receptors are located. Ultimately rate data from the laboratory studies being performed at INEEL will be incorporated into this model, as well as the model of the TAN site to provide a realistic prediction of degradation rates and plume longevity. Although identifying suitable TCE plumes and obtaining characterization data has taken longer than expected, this process has successfully identified the plumes needed for the detailed modeling activity without adversely impacting the project budget.
\end{abstract}

